\title{
Papers
}

\section{Value of low dose combination treatment with blood pressure lowering drugs: analysis of 354 randomised trials}

\author{
M R Law, N J Wald, J K Morris, R E Jordan
}

\begin{abstract}
Objective To determine the average reduction in blood pressure, prevalence of adverse effects, and reduction in risk of stroke and ischaemic heart disease events produced by the five main categories of blood pressure lowering drugs according to dose, singly and in combination.
\end{abstract}

Design Meta-analysis of 354 randomised double blind placebo controlled trials of thiazides, $\beta$ blockers, angiotensin converting enzyme (ACE) inhibitors, angiotensin II receptor antagonists, and calcium channel blockers in fixed dose.

Subjects 40000 treated patients and 16000 patients given placebo.

Main outcome measures Placebo adjusted reductions in systolic and diastolic blood pressure and prevalence of adverse effects, according to dose expressed as a multiple of the standard (recommended) doses of the drugs.

Results All five categories of drug produced similar reductions in blood pressure. The average reduction was $9.1 \mathrm{~mm} \mathrm{Hg}$ systolic and $5.5 \mathrm{~mm} \mathrm{Hg}$ diastolic at standard dose and $7.1 \mathrm{~mm} \mathrm{Hg}$ systolic and $4.4 \mathrm{~mm}$ $\mathrm{Hg}$ diastolic (20\% lower) at half standard dose. The drugs reduced blood pressure from all pretreatment levels, more so from higher levels; for a $10 \mathrm{~mm} \mathrm{Hg}$ higher blood pressure the reduction was $1.0 \mathrm{~mm} \mathrm{Hg}$ systolic and $1.1 \mathrm{~mm} \mathrm{Hg}$ diastolic greater. The blood pressure lowering effects of different categories of drugs were additive. Symptoms attributable to thiazides, $\beta$ blockers, and calcium channel blockers were strongly dose related; symptoms caused by ACE inhibitors (mainly cough) were not dose related. Angiotensin II receptor antagonists caused no excess of symptoms. The prevalence of symptoms with two drugs in combination was less than additive. Adverse metabolic effects (such as changes in cholesterol or potassium) were negligible at half standard dose. Conclusions Combination low dose drug treatment increases efficacy and reduces adverse effects. From the average blood pressure in people who have strokes $(150 / 90 \mathrm{~mm} \mathrm{Hg})$ three drugs at half standard dose are estimated to lower blood pressure by $20 \mathrm{~mm}$ $\mathrm{Hg}$ systolic and $11 \mathrm{~mm} \mathrm{Hg}$ diastolic and thereby reduce the risk of stroke by $63 \%$ and ischaemic heart disease events by $46 \%$ at age $60-69$.

\section{Introduction}

Lowering systolic blood pressure by $10 \mathrm{~mm} \mathrm{Hg}$ or diastolic blood pressure by $5 \mathrm{~mm} \mathrm{Hg}$ reduces the risk of stroke by about $35 \%$ and that of ischaemic heart disease (IHD) events by about $25 \%$ at age $65 .^{1-3}$ This applies across all levels of blood pressure in Western populations, not only in "hypertension." ${ }^{.7}$ Blood pressure lowering drugs should be more widely used, ${ }^{67}$ but which drugs are most appropriate, whether combinations of drugs should be used routinely, and whether lower doses than those currently used are preferable is not known. Large trials and systematic reviews have not examined the effects of variation in dose or of combination treatment. ${ }^{8-10}$ We report a systematic review of randomised placebo controlled trials of the five main categories of blood pressure lowering drugs to answer these questions.

\section{Methods}

We sought randomised placebo controlled trials that recorded the change in blood pressure in relation to a specified fixed dose of any thiazide, $\beta$ blocker, angiotensin converting enzyme (ACE) inhibitor, angiotensin II receptor antagonist, or calcium channel blocker. We searched the Medline, Cochrane Collaboration, and Web of Science databases. Details of the search procedure are on www.smd.qmul.ac.uk/ wolfson/bpchol. We used the same set of 354 trials identified and reported in our Health Technology Assessment monograph on the quantification of standard dose blood pressure treatment. ${ }^{7}$ In this paper we examine the effect of dose and combination treatment on efficacy and adverse effects. With the exceptions below we included all double blind trials, irrespective of the age or diseases of the participants. Most participants had high blood pressure (typically 90-110 $\mathrm{mm} \mathrm{Hg}$ diastolic), but trials of people with nonvascular conditions (such as thiazides for renal stones) provided evidence of efficacy at lower blood pressures.

We excluded trials with no placebo group, under two weeks' duration, titrating dose so that different patients received different doses, treating some control patients, testing drugs only in combination with other drugs, with non-randomised order of treatment and placebo periods in crossover trials, with most participants black (because of their different responses to some blood pressure lowering drugs ${ }^{11}$ ), or recruiting
Department of Environmental and Preventive Medicine, Wolfson Institute of Preventive

Preventive
Medicine, Barts and the London, Queen Mary's School of

Medicine and

Dentistry, University

of London, London

EC1M 6BQ

M R Law

professor

NJ Wald

professor

$\mathrm{J}$ K Morris

senior lecturer

R E Jordan

research assistant

Correspondence to: M R Law

m.r.law@qmul.ac.uk

bmj.com 2003;326:1427

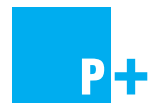

References to studies included and a table appear on bmi.com 
patients with heart failure, acute myocardial infarction, or other cardiovascular disorders. We included 354 trials. ${ }^{\text {w1-w343 }}$

We defined the efficacy of a drug as the reduction in systolic and diastolic blood pressure for a specified dose, expressed as the change in the treated group minus that in the placebo group (in crossover trials end treatment minus end placebo blood pressure). We categorised reductions in blood pressure as "peak" (2-6 hours after the last dose) or "trough" (22-26 hours; we did not include trough data from trials of drugs taken more than once daily ${ }^{7}$ ). Blood pressure was recorded sitting or supine.

In combining trial data we specified equivalent daily doses of different drugs as the "usual maintenance dose" in reference pharmacopoeias. ${ }^{12-14}$ We call this the standard dose. Where a range was given we took the lower dose as the standard dose.

We analysed the data by using Stata software. Parallel group trials and crossover trials yielded similar results, so we combined them. We fitted random effects regression models (separately for systolic and diastolic blood pressure) relating change in blood pressure in each treatment arm (treated minus placebo), weighted by the inverse of its variance, to category of drug, dose (expressed as a proportion of the standard dose), usual pretreatment blood pressure (estimated as that in the placebo group at the end of the trial to avoid regression to the mean), whether blood pressure measurements were peak or trough, and average age. We estimated the variance of the change in blood pressure, if not directly reported, from the standard error of blood pressure before and after the intervention as described previously. ${ }^{15}$ Data to calculate the variance were unavailable in 45 trials; we estimated it, given the

Table 1 Details of the 354 trials of blood pressure lowering drugs (adapted from Law et $\mathrm{al}^{7}$ )

\begin{tabular}{|c|c|c|}
\hline & Treatment & Placebo \\
\hline \multicolumn{3}{|c|}{ No of participants (No of different drugs) in trials of: } \\
\hline Thiazides (7) & 4502 & 2636 \\
\hline$\beta$ blockers (15) & 5189 & 2701 \\
\hline ACE inhibitors (12) & 9350 & 4712 \\
\hline $\begin{array}{l}\text { Angiotensin II receptor } \\
\text { antagonists (8) }\end{array}$ & 12840 & 5100 \\
\hline Calcium channel blockers (11) & 7998 & 3976 \\
\hline All trials & 39879 & $15817^{\star}$ \\
\hline \multicolumn{3}{|c|}{ No of treatment groups within trials of: } \\
\hline Thiazides & 104 & 64 \\
\hline$\beta$ blockers & 136 & 76 \\
\hline ACE inhibitors & 217 & 114 \\
\hline $\begin{array}{l}\text { Angiotensin II receptor } \\
\text { antagonists }\end{array}$ & 125 & 54 \\
\hline Calcium channel blockers & 209 & 122 \\
\hline All trials & 791 & $354^{*}$ \\
\hline \multicolumn{3}{|l|}{ Trial design: } \\
\hline Crossover & 219 & 125 \\
\hline $\begin{array}{l}\text { Parallel group } \\
\end{array}$ & 572 & 229 \\
\hline \multicolumn{3}{|c|}{ Mean (90\% range) pretreatment blood pressure $(\mathrm{mm} \mathrm{Hg}):$} \\
\hline Systolic & $154(139-170)$ & $154(139-170)$ \\
\hline Diastolic & $97(87-106)$ & $97(87-106)$ \\
\hline $\begin{array}{l}\text { Median (90\% range) duration } \\
\text { (weeks) }\end{array}$ & $4(2-12)$ & $4(2-12)$ \\
\hline Mean (90\% range) age (years) & $53(43-68)$ & $53(43-68)$ \\
\hline
\end{tabular}

ACE=angiotensin converting enzyme.

*Less than total of five categories because some trials compared drugs from two or more categories with the same placebo group. number of participants, from the average in all parallel group and crossover trials reporting variance.

The fit of the model was better with the dose expressed on a logarithmic (proportional) scale rather than on a linear scale, meaning that a halving of a dose was taken as equivalent to a doubling. We used straight lines (a quadratic fit was no better), so if fall in blood pressure was $a$ at standard dose and $a+b$ at twice standard dose, it would be $a-b$ at half standard dose. We thereby obtained placebo adjusted estimates of the blood pressure lowering effect of each category of drug according to dose. We compared these by using the indirect method. ${ }^{16}$

We estimated adverse effects attributable to the drugs as the difference in prevalence between treated and placebo groups in respect of the numbers of participants reporting one or more symptoms in trials recording all symptoms that might be drug related (313 of the 354 trials, $88 \%$ of all participants in the 354 trials) and the numbers of participants who stopped taking the tablets because of symptoms (305 trials, 84\% of all participants). We excluded headache because published evidence, and our own analysis, showed that fewer treated patients than placebo patients reported it. ${ }^{17}$ Adverse metabolic effects recorded were changes in serum cholesterol and its subfractions, potassium, glucose, and uric acid. The fit of the data to the model was again better with dose expressed on a logarithmic scale than a linear scale. We weighted the differences between treated and placebo groups in biochemical changes by the inverse of the variance and the differences in the proportions developing symptoms by the numbers of participants in the treated $\left(n_{1}\right)$ and placebo $\left(n_{2}\right)$ groups, as the inverse of $\sqrt{ }\left(1 / n_{1}{ }^{2}+1 / n_{2}{ }^{2}\right)$.

We analysed data on whether the combined effect of two drugs of different categories was additive with respect to blood pressure reduction and adverse effects. Within the 354 trials 50 trials (119 comparisons) tested the effect of drugs of two different categories separately and in combination. Of 238 treatment groups 84 tested thiazides, $26 \beta$ blockers, $71 \mathrm{ACE}$ inhibitors, 3 angiotensin II receptor antagonists, 44 calcium channel blockers, and 10 other drugs. We combined the 119 comparisons, weighting each by the inverse of its variance.

\section{Results}

Table 1 shows details of the 354 randomised trials identified. ${ }^{\text {wl-w343 }}$ The trials included 791 treatment groups, testing different drugs or different doses of the same drug, with about 40000 participants receiving treatment and 16000 receiving placebo. Tables giving further information on the 354 individual trials and the standard doses and costs of the drugs are on www.smd.qmul.ac.uk/wolfson/bpchol

\section{Efficacy}

\section{Single drugs}

Figure 1 shows the dose-response relations for the five categories of blood pressure lowering drug for systolic pressure (the plots for diastolic pressure were similar). The blood pressure reductions are the average of the peak and trough estimates and are placebo adjusted. The straight lines fit the data well. 

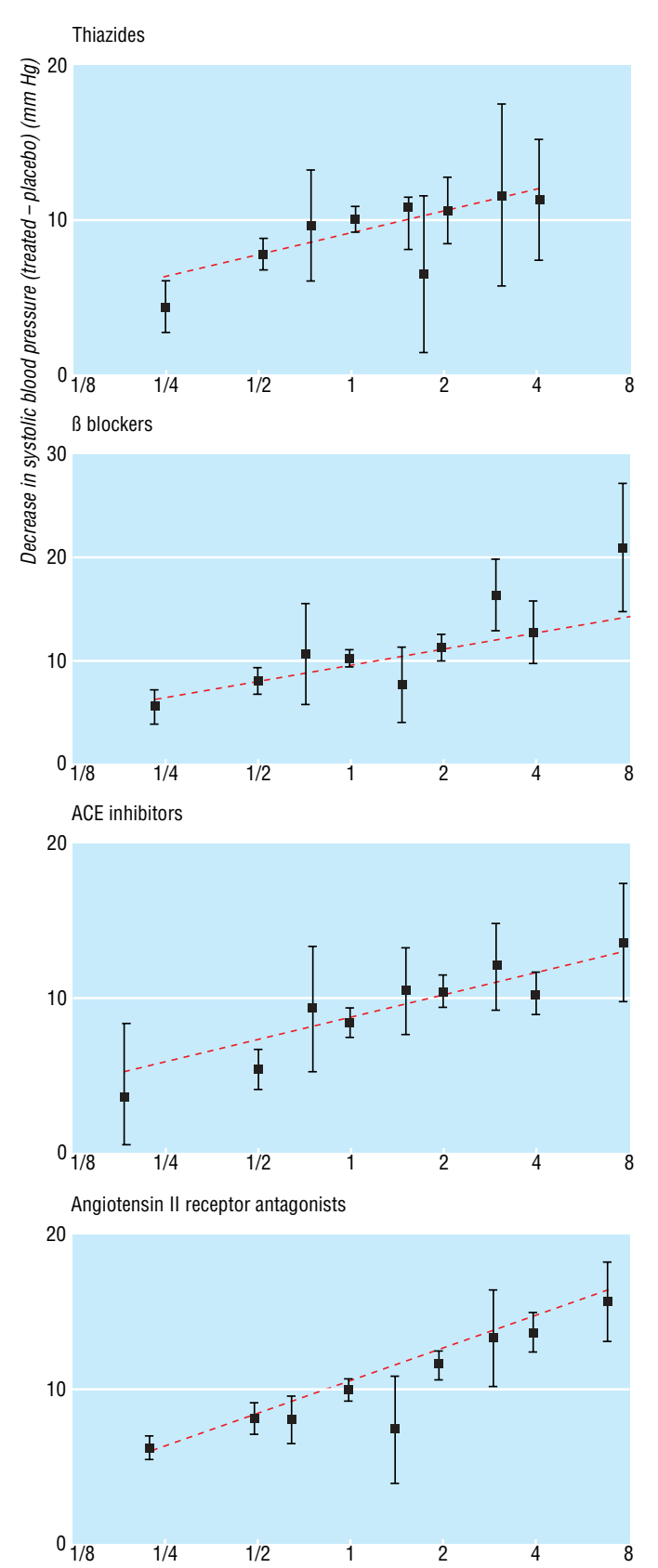

Calcium channel blockers

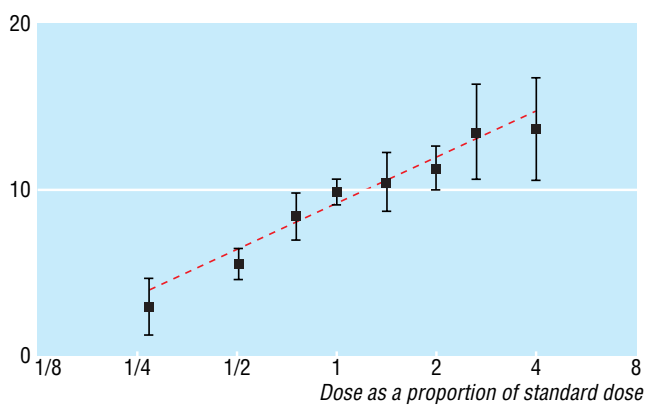

Fig 1 Average reductions in systolic blood pressure (adjusted for the change in the placebo group; with $95 \%$ confidence intervals) according to category of drug and dose as a proportion of standard (designated 1), from the results of 354 randomised trials, with the best fitting line. $A C E=$ angiotensin converting enzyme
Table 2 shows the average reductions in blood pressure over 24 hours produced by half standard, standard, and twice standard doses of the five categories of drug. Within each dose category the reductions were remarkably similar for different categories of drugs; few statistically significant differences existed, and no category of drug was materially more effective than another. Reductions with half standard dose were about $20 \%$ less than those with standard dose.

The individual drugs within each of the five categories produced similar reductions in blood pressure. No more "statistically significant" differences occurred than would be expected with so many comparisons. Some drugs may be more effective than others, but any differences are small, and in the absence of any prior hypothesis we could not identify them. The cheaper drugs within each category were as effective as the more expensive ones.

Within each of the five categories the average reductions in systolic and diastolic blood pressure recorded showed statistically significant heterogeneity across trials (greater variation than expected through chance). On average, $78 \%$ of the variance between trials in the reduction in systolic blood pressure and $69 \%$ of that in diastolic pressure were explained by the combined effects of differences in dose (as a proportion of standard), pretreatment blood pressure (see below), whether blood pressure was peak or trough, and differences between individual drugs (standard doses of different drugs within a category will not correspond exactly to equivalent pharmacological effects, and some drugs within a category may genuinely be better than others). We could not quantify differences between trials in proportions of participants who adhered to the protocol and in the extent to which non-adherent patients were included in the results or the effect of age.

Figure 2 shows that the drugs significantly lowered blood pressure from all pretreatment levels, although the reduction was greater (in absolute and proportional terms) from a higher level. The relation was well fitted by a straight line. If the pretreatment blood pressure was $10 \mathrm{~mm} \mathrm{Hg}$ higher, the reduction in blood pressure with one drug at standard dose increased on average by $1.0(95 \%$ confidence interval 0.7 to 1.2$) \mathrm{mm}$ $\mathrm{Hg}$ systolic and 1.1 (0.8 to 1.4$) \mathrm{mm} \mathrm{Hg}$ diastolic. The blood pressure reductions shown in table 2 apply to the average pretreatment blood pressure in all the trials of $154 \mathrm{~mm} \mathrm{Hg}$ systolic and $97 \mathrm{~mm} \mathrm{Hg}$ diastolic. No effect of age was evident, but age varied little across trials.

\section{Combinations of drugs}

Fifty trials (including 119 placebo controlled comparisons) compared drugs from two categories, separately and together. Figure 3 shows the observed placebo adjusted reductions in blood pressure with two drugs taken together plotted against the expected reductions from adding the reductions produced by each drug alone. Overall the points lie close to the $45^{\circ}$ line of identity between observed and expected across a wide range of blood pressure reductions. Table 3 shows that the sum of the average reductions in blood pressure with each drug used alone is close to the observed effect of the two drugs used in combination, indicating 
Table 2 Efficacy: average reductions* in blood pressure over 24 hours (treated minus placebo) according to category of drug and dose

\begin{tabular}{|c|c|c|c|c|}
\hline \multirow[b]{2}{*}{ Category of drugt } & \multicolumn{3}{|c|}{ Fall in blood pressure $(\mathrm{mm} \mathrm{Hg})(95 \% \mathrm{Cl})$} & \multirow{2}{*}{$\begin{array}{l}\text { Half standard } v \text { standard: } \\
\text { proportional difference (\%) }\end{array}$} \\
\hline & Half standard dose & Standard dose & Twice standard dose & \\
\hline \multicolumn{5}{|l|}{ Systolic blood pressure } \\
\hline \multicolumn{5}{|l|}{ Category: } \\
\hline Thiazides & $7.4(6.6$ to 8.2$)$ & $8.8(8.3$ to 9.4$)$ & 10.3 (9.4 to 11.2$)$ & 16 \\
\hline$\beta$ blockers & $7.4(6.6$ to 8.3$)$ & 9.2 (8.6 to 9.9$)$ & $11.1(10.2$ to 12.0$)$ & 20 \\
\hline ACE inhibitors & $6.9(6.1$ to 7.8$)$ & $8.5(7.9$ to 9.0$)$ & $10.0(9.5$ to 10.4$)$ & 19 \\
\hline Angiotensin II receptor antagonists & 7.8 (7.1 to 8.6$)$ & $10.3(9.9$ to 10.8$)$ & 12.3 (11.7 to 12.8$)$ & 24 \\
\hline Calcium channel blockers & $5.9(5.2$ to 6.6$)$ & 8.8 (8.3 to 9.2$)$ & $11.7(11.0$ to 12.3$)$ & 33 \\
\hline All categories: average & $7.1(6.8$ to 7.5$)$ & 9.1 (8.8 to 9.3$)$ & $10.9(10.7$ to 11.2$)$ & 22 \\
\hline \multicolumn{5}{|l|}{ Diastolic blood pressure } \\
\hline \multicolumn{5}{|l|}{ Category: } \\
\hline Thiazides & 3.7 (3.2 to 4.2$)$ & $4.4(4.0$ to 4.8$)$ & 5.0 (4.4 to 5.7$)$ & 16 \\
\hline$\beta$ blockers & $5.6(5.0$ to 6.2$)$ & $6.7(6.2$ to 7.1$)$ & $7.8(7.1$ to 8.4$)$ & 16 \\
\hline ACE inhibitors & 3.7 (3.2 to 4.2$)$ & $4.7(4.4$ to 5.0$)$ & $5.7(5.4$ to 6.0$)$ & 21 \\
\hline Angiotensin II receptor antagonists & $4.5(4.2$ to 4.8$)$ & 5.7 (5.4 to 6.0$)$ & 6.5 (6.2 to 6.8$)$ & 21 \\
\hline Calcium channel blockers & $3.9(3.5$ to 4.4$)$ & 5.9 (5.6 to 6.2$)$ & $7.9(7.5$ to 8.3$)$ & 34 \\
\hline All categories: average & 4.4 (4.2 to 4.6$)$ & 5.5 (5.4 to 5.7$)$ & 6.5 (6.3 to 6.7$)$ & 20 \\
\hline
\end{tabular}

ACE=angiotensin converting enzyme.

${ }^{*}$ Estimates are average over 24 hours from combining separate peak and trough estimates.

†Examples of standard daily dose of one drug in each category: bendroflumethazide $2.5 \mathrm{mg}$, atenolol $50 \mathrm{mg}$, lisinopril $10 \mathrm{mg}$, valsartan $80 \mathrm{mg}$, amlodipine $5 \mathrm{mg}$. See www.smd.qmul.ac.uk/wolfson/bpchol for standard doses of all drugs.

an additive effect. The 119 comparisons showed an additive effect for six of the 10 possible combinations. Only one trial (which was inconclusive) studied $\beta$ blockers with ACE inhibitors, ${ }^{\text {w76 }}$ and no trial used angiotensin III receptor antagonists with drugs other than thiazides. The independent effects on blood pressure are not surprising as the different categories of drugs have different modes of action, apart from ACE inhibitors and angiotensin II receptor antagonists (and even these may have additive effects ${ }^{18}$ ). Although no trial has studied the effect of three drugs in combination, the additive effect of many combinations

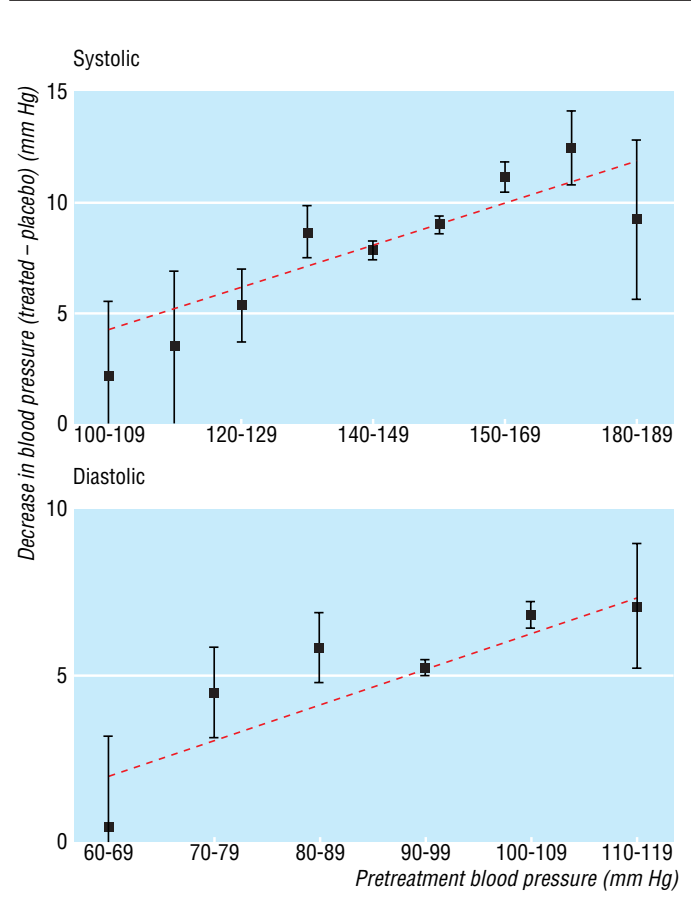

Fig 2 Average reduction in blood pressure (adjusted for the change in the placebo group; with $95 \%$ confidence intervals) according to the usual pretreatment blood pressure, from the results of 354 randomised trials, with the best fitting line

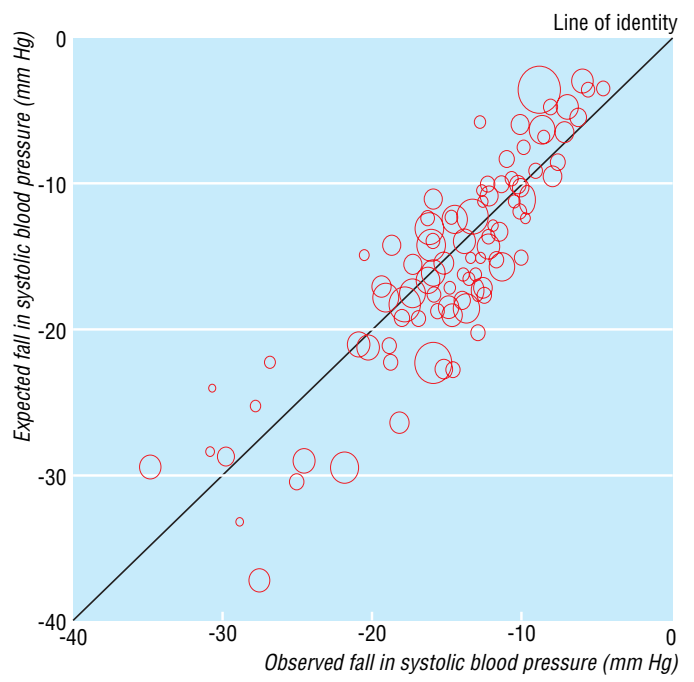

Fig 3 Trials testing two blood pressure lowering drugs separately and in combination: observed placebo adjusted reduction in systolic blood pressure (treated minus placebo) with two drugs used in combination plotted against the expected reduction in blood pressure from adding the reductions produced by each drug alone. The area of each symbol is inversely proportional to the variance in the trial it represents. Adapted from Law et al ${ }^{7}$

of two drugs suggests that the effect of three drugs in combination would also be additive.

Table 4 shows the expected reduction in blood pressure with one, two, and three blood pressure lowering drugs used at half standard dose. The reductions are adjusted from those in table 2 to a usual pretreatment blood pressure of 150/90 mm Hg, which cohort studies show is about average in people who have a stroke or IHD event. ${ }^{7}$ The reductions with two and three drugs are based on the additive effect (table 3) but adjusted for the lower pretreatment blood pressure for each successive drug (fig 2). Three drugs together would be expected to lower blood pressure by about $20 \mathrm{~mm} \mathrm{Hg}$ systolic and $11 \mathrm{~mm} \mathrm{Hg}$ diastolic. 

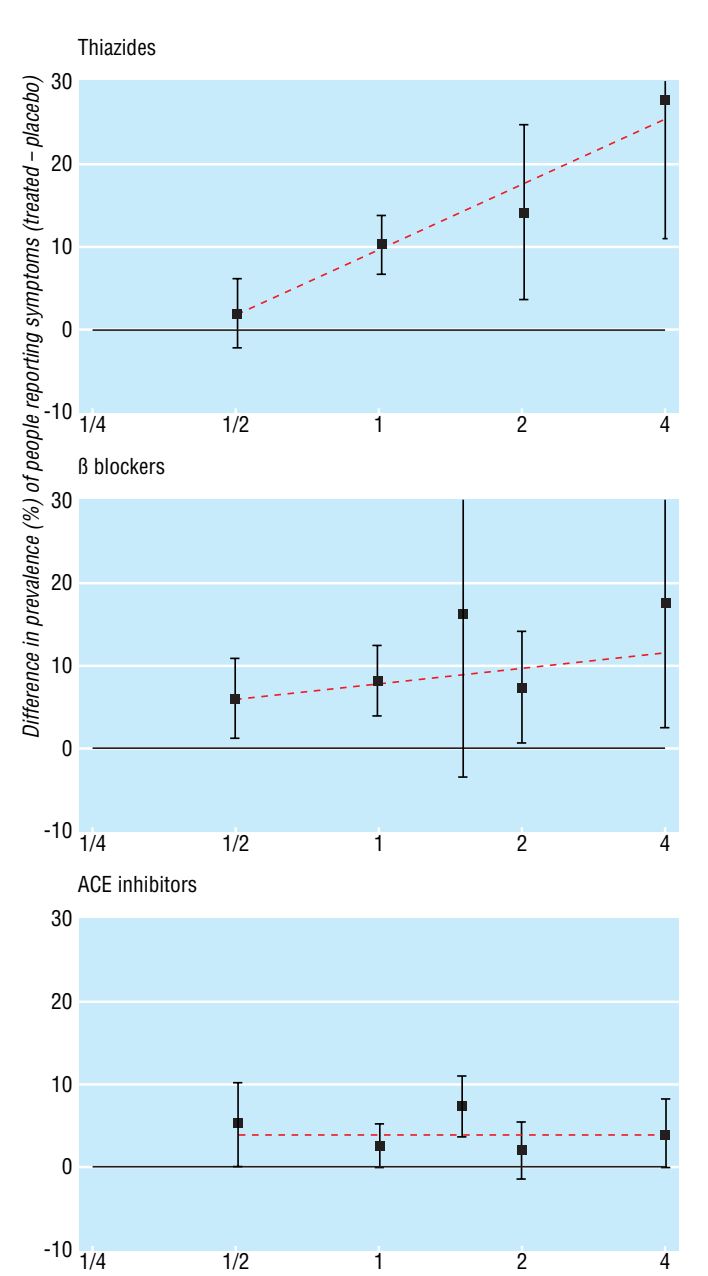

Angiotensin II receptor antagonists

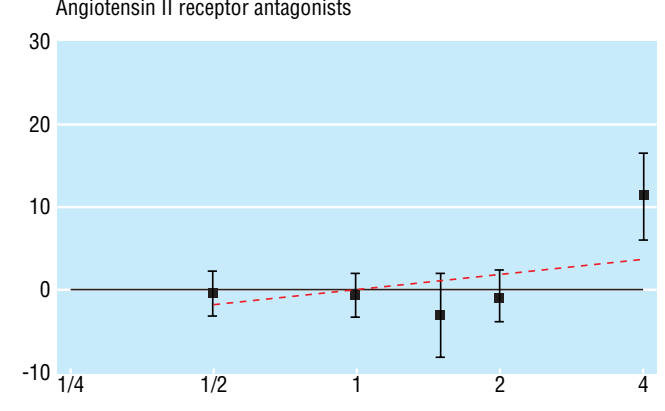

Calcium channel blockers

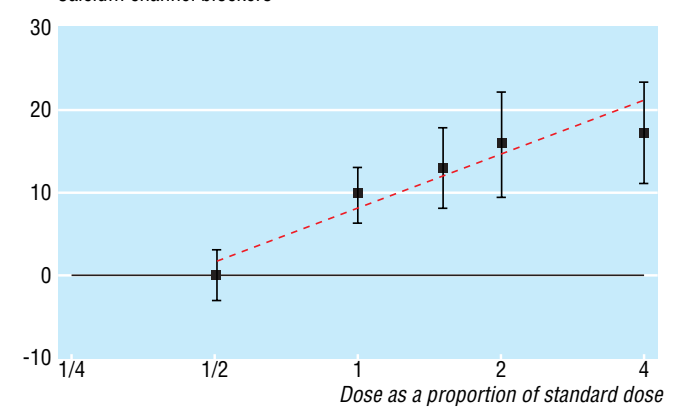

Fig 4 -Proportions of people reporting one or more symptoms attributable to treatment (treated minus placebo; with 95\% confidence interval) according to category of drug and dose as a proportion of standard (designated 1). ACE=angiotensin converting enzyme
Table 3 Efficacy: effects of two different drugs on blood pressure separately and in combination (summary results from 119 randomised placebo controlled comparisons; adapted from Law et $\mathrm{a}^{7}$ )

\begin{tabular}{|c|c|c|}
\hline \multirow[b]{2}{*}{ Treatment } & \multicolumn{2}{|c|}{$\begin{array}{l}\text { Average (SE) fall in blood pressure }(\mathrm{mm} \mathrm{Hg}) \text { (treated minus } \\
\text { placebo) }\end{array}$} \\
\hline & Systolic & Diastolic \\
\hline \multicolumn{3}{|l|}{ Observed } \\
\hline "First" drug alone & $7.0(0.4)$ & $4.1(0.3)$ \\
\hline "Second "drug alone & $8.1(0.3)$ & $4.6(0.3)$ \\
\hline Both drugs together & $14.6(0.5)$ & $8.6(0.4)$ \\
\hline \multicolumn{3}{|l|}{ Expected } \\
\hline $\begin{array}{l}\text { Sum of first and second drugs } \\
\text { alone }\end{array}$ & 15.1 & 8.7 \\
\hline $\begin{array}{l}\text { Difference between observed and } \\
\text { expected }(95 \% \mathrm{Cl})\end{array}$ & $-0.5(-1.4$ to 0.4$)$ & $-0.1(-1.0$ to 0.8$)$ \\
\hline
\end{tabular}

Table 4 Efficacy: blood pressure lowering effects of drugs when used at half standard dose separately and in combination

\begin{tabular}{lccc} 
& \multicolumn{3}{c}{ Blood pressure reduction* } \\
\cline { 2 - 4 } & One drug & Cl) \\
\hline Systolic blood pressure $(\mathrm{mm} \mathrm{Hg})$ & $6.7(6.1$ to 7.2$)$ & $13.3(12.4$ to 14.1$)$ & $19.9(18.5$ to 21.3$)$ \\
\hline Diastolic blood pressure $(\mathrm{mm} \mathrm{Hg})$ & $3.7(3.1$ to 4.3$)$ & $7.3(6.2$ to 8.3$)$ & $10.7(9.1$ to 12.4$)$ \\
\hline
\end{tabular}

* Reductions in blood pressure adjusted to a usual pretreatment blood pressure of $150 / 90 \mathrm{~mm} \mathrm{Hg}$, the average blood pressure in people aged 50-69 years who have a stroke or ischaemic heart disease event. ${ }^{7}$

\section{Adverse effects}

Single drugs

Figure 4 shows the difference in the proportions of participants who experienced one or more symptoms between treated and placebo groups according to dose. The straight lines generally fit the data well, and a clear dose-response relation can be seen for three categories of drugs. Table 5, based on the straight lines in figure 4, shows that thiazides and calcium channel blockers caused symptoms infrequently $(2.0 \%$ and $1.6 \%)$ at half standard dose but commonly $(9.9 \%$ and $8.3 \%)$ at standard dose $(\mathrm{P}$ (for trend) <0.001). $\beta$ blockers caused symptoms in $5.5 \%$ of patients at half standard dose and in $7.5 \%$ at standard dose $(\mathrm{P}=0.04)$. Cough $(3.9 \%)$ was virtually the only symptom with ACE inhibitors and did not vary with dose, a finding consistent with earlier studies. ${ }^{19}{ }^{20}$ No excess of symptoms occurred at standard dose or half standard dose of angiotensin II receptor antagonists; in particular, no excess of cough occurred. ${ }^{7}$

Trials of crossover design showed that symptoms are reversible on stopping the drugs. The trials in this analysis were short (a few weeks), but one trial showed that the prevalence of symptoms caused by a thiazide or a $\beta$ blocker (treated minus placebo) was in general no greater after two years than after 12 weeks. ${ }^{21}$ Thiazides were the only drugs to affect sexual function, a finding confirmed in a large long term trial..$^{22}$

The prevalence of symptoms sufficiently severe to stop treatment (treated minus placebo) was $0.8 \%(0.3 \%$ to $1.4 \%$ ) for $\beta$ blockers, $0.1 \%$ for thiazides and ACE inhibitors, and zero for angiotensin II receptor antagonists (table 6). Sufficient trial data were available for calcium channel blockers to allow examination of a dose effect: no excess risk occurred at half standard dose (table 6$)$, but the risk was $1.4 \%(0.4 \%$ to $2.4 \%)$ at standard dose and $4.5 \%$ (2.4 to $6.6 \%)$ at twice standard dose.

The metabolic effects of thiazides were dose dependent (table A on bmj.com). The increase in serum cholesterol was $1 \%$ at half standard dose, $3 \%$ at 
Table 5 Adverse effects of drugs: percentage of people with one or more symptoms attributable to treatment ${ }^{\star}$, according to category of drug and dose, in randomised trials

\begin{tabular}{lcccc} 
& & \multicolumn{2}{c}{ Percentage $\mathbf{( 9 5 \%} \mathbf{~ C l )}$ with symptoms (treated minus placebo)† } \\
\cline { 2 - 5 } Category of drug & No of trials & Half standard dose & Standard dose & Twice standard dose \\
\hline Thiazides & 59 & $2.0(-2.2$ to 6.3$)$ & $9.9(6.6$ to 13.2$)$ & $17.8(11.5$ to 24.2$)$ \\
\hline$\beta$ blockers & 62 & $5.5(0.3$ to 10.7$)$ & $7.5(4.0$ to 10.9$)$ & $9.4(3.6$ to 15.2$)$ \\
\hline ACE inhibitors & 96 & $3.9(-3.7$ to 11.6$)$ & $3.9(-0.5$ to 8.3$)$ & $3.9(-0.2$ to 8.0$)$ \\
\hline Angiotensin II receptor antagonists & 44 & $-1.8(-10.2$ to 6.5$)$ & $0(-5.4$ to 5.4$)$ & $1.9(-5.6$ to 9.3$)$ \\
\hline Calcium channel blockers & 96 & $1.6(-3.5$ to 6.7$)$ & $8.3(4.8$ to 11.8$)$ & $14.9(9.8$ to 20.1$)$ \\
\hline
\end{tabular}

\section{ACE=angiotensin converting enzyme.}

${ }^{*}$ Calculated as difference between treated and placebo groups in proportion of participants who developed one or more symptoms, excluding headaches, which were significantly less common in people receiving treatment.

†Commonest symptoms: thiazides—dizziness, impotence, nausea, muscle cramp; $\beta$ blockers—cold extremities, fatigue, nausea; ACE inhibitors—cough; calcium channel blockers-flushing, ankle oedema, dizziness. ${ }^{7}$

standard dose, and 5\% at twice standard dose. Thiazides did not materially affect low density lipoprotein cholesterol or high density lipoprotein cholesterol; the increase was in the very low density lipoprotein subfraction, which is associated only weakly with atherogenesis.

Thiazides at half standard dose also had a small effect in decreasing serum potassium $(-6 \%)$, increasing blood glucose (1\%), and increasing serum uric acid (9\%) (table A on bmj.com). Even at standard doses the loss of total body potassium is small (about 200 $\mathrm{mmol} / \mathrm{l}$ ) and does not increase the risk of cardiac arrhythmia. ${ }^{723-27}$ The increase in blood glucose is reversible, with no excess risk of overt diabetes. ${ }^{28} 29$ From the association between serum uric acid and gout reported in a cohort study of men (adjusted for age and other confounding factors), the $9 \%$ average increase in uric acid at half standard dose would be expected to increase the incidence of gout by $58 \%$ ( $45 \%$ to $71 \%$ ), from a background incidence of about 1.5 per 1000 per year to 2.4 per 1000 per year (an absolute increase of under 1 per 1000 per year). ${ }^{30}{ }^{31}$ Gout is less common in women, ${ }^{31}$ and the absolute increase would be about 1 per 10000 per year.

Insufficient data were available to examine the effect by dose for the other four drug categories. ${ }^{7}$ In six trials of $\beta$ blockers (average dose was $1.4 \times$ standard) total serum cholesterol decreased by $3 \%$, comprising separate small decreases in low density and high density lipoprotein cholesterol (similar to a previous finding ${ }^{32}$ ). $\beta$ blockers produced a $2 \%$ ( $1 \%$ to $4 \%$ ) increase in serum potassium on average (10 trials) and no significant change in blood glucose or uric acid. ACE inhibitors and angiotensin II receptor antagonists increase serum potassium because of their effect on aldosterone: in 18 trials of either the average increase was $3 \%$ (2\% to $5 \%)$. Calcium channel blockers did not

Table 6 Adverse effects of drugs: percentage of people with symptoms attributable to treatment sufficient to stop taking the tablets, according to category of drug in randomised trials (adapted from Law et al')

\begin{tabular}{lccc} 
Category of drug & No of trials & $\begin{array}{c}\text { Percentage } \mathbf{9 5 \%} \text { CI) who } \\
\text { stopped taking tablets } \\
\text { multiple of standard }\end{array}$ & $\begin{array}{c}\text { tose as } \\
\text { of symptoms (treated } \\
\text { minus placebo) }\end{array}$ \\
\hline Thiazides & 57 & 1.0 & $0.1(-0.7 \text { to } 0.9)^{\star}$ \\
\hline$\beta$ blockers & 62 & 1.3 & $0.8(0.3$ to 1.4$)$ \\
\hline ACE inhibitors & 92 & 1.9 & $0.1(-0.3 \text { to } 0.6)^{\star}$ \\
\hline $\begin{array}{l}\text { Angiotensin II receptor } \\
\text { antagonists }\end{array}$ & 44 & 1.3 & $-0.2(-0.5 \text { to } 0.2)^{\star}$ \\
\hline Calcium channel blockers & 92 & 0.5 & $-1.3(-2.6 \text { to } 0.0)^{\star}$ \\
\hline
\end{tabular}

$\mathrm{ACE}=$ angiotensin converting enzyme.

*Not statistically significant; however, upper confidence interval is informative. increase blood glucose (95\% confidence interval 2\% lower to 5\% higher; 10 trials), and no increase in diabetes occurred in a six year study. ${ }^{28}$

\section{Combinations of drugs}

Of the 50 placebo controlled trials testing drugs of two different categories separately and in combination, 33 reported adverse effects. In 66 trial arms single drugs caused symptoms in $5.2 \% \quad(3.6 \%$ to $6.6 \%)$ of participants on average (prevalence in treated group minus placebo). In 33 trial arms two drugs together caused symptoms in $7.5 \%$ (5.8\% to 9.3\%), which is significantly lower than the value of $10.4 \%$ (twice $5.2 \%$ ) expected with an additive effect $(\mathrm{P}=0.03)$. One drug does not therefore potentiate the adverse effects of another. The lower than expected prevalence with two drugs may suggest that some people are more likely than others to either experience or report symptoms.

In trials testing different drugs separately and together the serum potassium lowering effect of thiazides was offset by $\beta$ blockers, ${ }^{\mathrm{w} 29, \mathrm{w} 36, \mathrm{w} \text { (99,w51 }}$ ACE inhibitors, ${ }^{\mathrm{w}, \mathrm{w} 26, w 34}$ and angiotensin II receptor

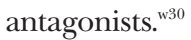

\section{Discussion}

The five categories of drugs produced similar reductions in blood pressure and were effective from all pretreatment levels (fig 2), reinforcing the view that use of blood pressure lowering drugs should be determined by a person's overall level of risk rather than the blood pressure alone. ${ }^{6}$ Reduction in blood pressure was only about $20 \%$ less at half standard dose than at standard dose, but adverse effects were much less common. Efficacy of drugs in combination was additive, but prevalence of adverse effects was less than additive. Combinations of two or three drugs at low dose are therefore preferable to one or two drugs at standard dose. Within each category no one drug was better than another; choice of drug should be based on low cost and once daily administration. Everyone at increased risk would benefit from using three drugs, apart from those with contraindications to a particular drug.

Table 7 shows the expected reductions in the incidence of stroke and IHD events from using blood pressure lowering drugs at half standard dose separately and in combination. The calculations used the blood pressure reductions from table 4 and the estimates of the association between blood pressure and disease events at age 60-69 from the Prospective Studies Collaboration (these are similar to those from 
Table 7 Effects of blood pressure lowering drugs on reducing the incidence of stroke and ischaemic heart disease events when used separately and in combination at half standard dose*

\begin{tabular}{lccc} 
& & Percentage $\mathbf{( 9 5 \%}$ Cl) reduction in incidence & \\
\cline { 2 - 4 } Disease & One drug & Two drugs & Three drugs \\
\hline Stroke & $29(26$ to 31$)$ & $49(42$ to 55$)$ & 63 (55 to 70$)$ \\
\hline Ischaemic heart disease events & $19(17$ to 21$)$ & $34(29$ to 40$)$ & 46 (39 to 53$)$
\end{tabular}

${ }^{*}$ Calculated from reductions in blood pressure in table 4 and estimates of association between blood pressure and disease events at age 60-69 years from the Prospective Studies Collaboration.

\section{What is already known on this topic}

Blood pressure lowering drugs prevent stroke and heart disease, but whether they are best used in combination, and if so at what dose, is not known

\section{What this study adds}

The efficacies of five categories of drug are similar at standard doses and only $20 \%$ lower at half standard doses; adverse effects are much less common at half standard dose than at standard dose

The drugs are effective from all pretreatment levels of blood pressure

Reductions in blood pressure with drugs in combination are additive; adverse effects are less than additive

Using three blood pressure lowering drugs in low dose combination would reduce stroke by two thirds and heart disease by half

other pooled cohort study data and meta-analyses of randomised trials). ${ }^{1-4} 7$ The estimates are based on diastolic pressure, but those based on the average of systolic and diastolic pressures (probably the best measure to use $^{1}$ ) are similar. Three drugs in combination at half standard dose reduce the risk of stroke by $63 \%$ and IHD events by $46 \%$. Use of one of the three drugs at standard dose (an ACE inhibitor or angiotensin II receptor antagonist because adverse effects were no higher at standard than half standard dose) reduces blood pressure by a further $2.3 \mathrm{~mm} \mathrm{Hg}$ systolic and $1.0 \mathrm{~mm} \mathrm{Hg}$ diastolic and reduces the risk of stroke by $66 \%$ and IHD events by $49 \%$.

All but two of our conclusions are based on direct evidence. No trial directly studied the combined effect of three drugs on blood pressure, but an additive effect follows because an additive effect has been shown for many combinations of two drugs. Randomised trials have not tested the combined effect of two or three drugs on the incidence of stroke and IHD events, but the cohort studies show a continuous relation between blood pressure and the risk of these diseases, ${ }^{1-3}$ confirmed by randomised trials of single drug treatment from a wide range of pretreatment levels. ${ }^{4-7}$

Three drugs in low dose combination have a large preventive effect, reducing the risk of stroke by two thirds and IHD events by half, with a low prevalence of adverse effects. Low dose combination treatment should be used as a first option in lowering blood pressure, and the indications for using blood pressure lowering drugs should be broadened.
Contributors: MRL and REJ abstracted the data, and JKM did the statistical analysis. All four authors interpreted the results and wrote the paper. MRL is the guarantor.

Funding: None.

Competing interests: NJW and MRL have filed a patent application on the formula of a combined pill to simultaneously reduce four cardiovascular risk factors.

1 Prospective Studies Collaboration. Age-specific relevance of usual blood pressure to vascular mortality: a meta-analysis of individual data for one million adults in 61 prospective studies. Lancet 2002;360:1903-13.

2 Asia Pacific Cohort Studies Collaboration. Blood pressure and cardiovascular disease in the Asia Pacific region. J Hypertens 2003;21:707-16.

3 MacMahon S, Peto R, Cutler J, Collins R, Sorlie P, Neaton J, et al. Blood pressure, stroke and coronary heart disease: part 1, prolonged differences in blood pressure: prospective observational studies corrected for the in blood pressure: prospective observational s

4 Collins R, Peto R, MacMahon S, Hebert P, Fiebach NH, Eberlein KA, et al. Blood pressure, stroke, and coronary heart disease: part 2, short-term reductions in blood pressure: overview of randomised drug trials in their epidemiological context. Lancet 1990;335:827-38

5 PROGRESS Collaborative Group. Randomised trial of a perindoprilbased blood-pressure-lowering regimen among 6105 individuals with previous stroke or transient ischaemic attack. Lancet 2001;358:1033-41.

6 Law MR, Wald NJ. Risk factor thresholds: their existence under scrutiny BMJ 2002;324:1570-6.

7 Law M, Wald N, Morris J. Lowering blood pressure to prevent myocardial infarction and strokes: a new preventive strategy. Health Technol Assess 2003 ; in press.

8 Major outcomes in high-risk hypertensive patients randomised to angiotensin-converting enzyme inhibitor or calcium channel blocker vs diuretic: the antihypertensive and lipid-lowering treatment to prevent heart attack trial (ALLHAT). JAMA 2002;288:2981-97.

9 Blood Pressure Lowering Treatment Trialists' Collaboration. Effects of ACE inhibitors, calcium antagonists, and other blood-pressure-lowering drugs: results of prospectively designed overviews of randomised trials. Lancet 2000;355:1955-64.

10 Psaty BM, Smith NL, Siscovick DS, Koepsell TD, Weiss NS, Heckbert SR, et al. Health outcomes associated with antihypertensive therapies used as first-line agents. JAMA 1997;277:739-45.

11 Seedat YK. Varying responses to hypotensive agents in different racial groups: black versus white differences.J Hypertens 1989;7:515-8.

12 British Medical Association, Royal Pharmaceutical Society of Great Britain. British National Formulary:September 2001. London: BMJ Books, 2001. 13 Reynolds JEF, ed. Martindale: the extra pharmacopoeia. London: Royal Pharmaceutical Society, 1996.

14 Monthly Index of Medical Specialties (MIMS): August 2001. London: Haymarket Medical, 2001

15 Elbourne DR, Altman DG, Higgins JPT, Curtin F, Worthington HV, Vail A. Meta-analyses involving cross-over trials: methodological issues. Int J Epidemiol 2002;31:140-9.

16 Bucher H, Guyatt G, Griffith L, Walter S. The results of direct and indirect treatment comparisons in meta-analysis of randomised controlled trials. J Clin Epidemiol 1997;50:683-91.

17 Hansson L, Smith DHG, Reeves R, Lapuerta P. Headache in mild-to-moderate hypertension and its reduction by irbesartan therapy. Arch Intern Med 2000;160:1654-8.

18 Azizi M, Chatellier G, Guyene T-T, Murieta-Geoffroy D, Ménard J. Additive effects of combined angiotensin II antagonism on blood pressure and renin release in sodium-depleted normotensives. Circulation 1995;92:825-34.

19 Coulter DM, Edwards IR. Cough associated with captopril and enalapril. BMJ 1987;294:1521-3.

20 Israili ZH, Dallas Hall Z. Cough and angioneurotic edema associates with angiotensin-converting enzyme inhibitor therapy. Ann Intern Med 1992;117:234-42.

21 Medical Research Council Working Party on Mild to Moderate Hypertension. Adverse reactions to bendrofluazide and propranolol for the treatment of mild hypertension. Lancet 1981;2:539-43.

22 Grimm RH, Grandits GA, Prineas RJ, McDonald RH, Lewis CE, Flack JM, et al. Long-term effects on sexual function of five antihypertensive drugs and nutritional hygienic treatment in hypertensive men and women. Hypertension 1997;29:8-14.

23 Freis ED. Critique of the clinical importance of diuretic-induced hypokalemia and elevated cholesterol level. Arch Intern Med 1989;149:2640-8.

24 Kaplan NM, Carnegie A, Raskin P, Heller JA, Simmons M. Potassium supplementation in hypertensive patients with diuretic-induced hypokalemia. N Engl J Med 1985;312:746-9.

25 Papademetriou V, Price M, Johnson E, Smith M, Freis ED. Early changes in plasma and urinary potassium in diuretic-treated patients with systemic hypertension. Am J Cardiol 1984;54:1015-9. 
26 Wilkinson PR, Issler H, Hesp R, Raftery EB. Total body and serum potassium during prolonged thiazide therapy for essential hypertension. Lancet 1975;1:759-62.

27 Papademetriou V, Burris JF, Notargiacomo A, Fletcher RD, Freis ED. Thiazide therapy is not a cause of arrhythmia in patients with systemic hypertension. Arch Intern Med 1988;148:1272-6.

28 Gress TW, Nieto FJ, Shahar E, Wofford MR, Brancati FL. Hypertension and antihypertensive therapy as risk factors for type 2 diabetes mellitus. N Engl J Med 2000;342:905-12.

29 Murphy MB, Lewis PJ, Kohner E, Schumer B, Dollery CT. Glucose intolerance in hypertensive patients treated with diuretics; a fourteen-yea follow-up. Lancet 1982;2:1293-5.
30 Campion EW, Glynn RJ, DeLabry LO. Asymptomatic hyperuricemia: risks and consequences in the normative aging study. Am J Med 1987;82:421-6.

31 Greenberg G, Brennan PJ, Miall WE. Effects of diuretic and beta-blocker therapy in the Medical Research Council trial. Am J Med 1984;76(2A): 45-51.

32 Grimm RH, Flack JM, Grandits GA, Elmer PJ, Neaton JD, Cutler JA, et al Long-term effects on plasma lipids of diet and drugs to treat hypertension. JAMA 1996;275:1549-55.

(Accepted 8 April 2003) 